\title{
VIABILIDADE DE SUBSTRATOS ALTERNATIVOS NA PRODUÇÃO DE MUDAS DE TOMATEIRO
}

Danyllo Denner de Almeida Costa ${ }^{1}$; Rodrigo de Morais Borges ${ }^{2}$; Luciana Corrêa Moraes $^{3}$; Sandy Spineli Silva ${ }^{4}$; José Carlos Mazetto Júnior ${ }^{5}$

1. Engenheiro Agrônomo, mestrando do Programa de Pós-Graduação em Agronomia (PPGA) do Instituto de Ciências Agrárias (ICIAG) da Universidade Federal de Uberlândia (UFU) (danyllo.denner@hotmail.com);

2. Engenheiro Agrônomo graduado pelo Instituto Federal do Triângulo Mineiro -

Campus Uberaba;

3. Engenheira Agrônoma, mestranda do PPGA do ICIAG da UFU;

4. Engenheira Agrônoma, mestranda do Departamento de Entomologia e Acarologia da Escola Superior de Agricultura "Luiz de Queiroz" (Esalq/USP);

5. Engenheiro Agrônomo, mestrando do PPGA do ICIAG da UFU.

Recebido em: 02/10/2017 - Aprovado em: 21/11/2017 - Publicado em: 05/12/2017 DOI: 10.18677/EnciBio_2017B68

Um dos representantes mais importantes do grupo das hortaliças, o tomate durante a fase de muda tem seu custo alavancado com os substratos, atraindo a atenção para alternativas produtivas e viáveis economicamente. Assim, objetivou-se avaliar a produção de mudas de tomate em substrato constituído por bagaço de cana e vermicomposto. O experimento foi conduzido em ambiente protegido no IFTM Campus Uberaba em delineamento de blocos ao acaso com seis tratamentos: substrato comercial ( $\mathrm{T}) ; 100 \%$ vermicomposto $(\mathrm{T} 1) ; 75 \%$ vermicomposto $+25 \%$ bagaço de cana (BC) (T2); $50 \%$ vermicomposto $+50 \%$ BC (T3); $25 \%$ vermicomposto $+75 \%$ BC (T4) e 100\% BC (T5), com quatro repetições em bandejas de 128 células. Foram avaliadas massas fresca e seca de raiz e parte aérea, comprimentos de raiz e parte aérea, diâmetro de coleto, número de folhas e Índice de Qualidade de Dickson (IQD). Foram observados efeitos significativos do substrato para todas as características analisadas. T5 se apresentou, no geral, inferior para todas as características, especialmente em número de folhas. Em contrapartida, as médias de T, T1 e T2 foram superiores em massa fresca de raiz, enquanto para as demais características os mesmos tratamentos se apresentaram igualmente eficientes a T3 e T4. A testemunha não se apresentou inferior em nenhuma característica, assim como T1, T2 e T3. Conclui-se, portanto, que o vermicomposto se mostrou benéfico de modo geral, entretanto considerando todas as características avaliadas e sendo evidenciado no IQD, os substratos contendo de 100 até $75 \%$ de vermicomposto, junto ao bagaço, se mostraram potencialmente viáveis.

PALAVRAS-CHAVE: Lycopersicon esculentum Mill., Resíduos de agroindústria, Substratos alternativos. 


\title{
VIABILITY OF ALTERNATIVE SUBSTRATES FOR PRODUCING TOMATO SEEDLINGS
}

\begin{abstract}
Tomato is one of the most important in the vegetable group. While seedlings, the substrate increases the total cost of the production, attracting attention to economic viable alternatives. Thus, this study aimed to evaluate the production of tomato seedlings in substrate constituted by sugarcane bagasse and vermicompost. The experiment was conducted in a greenhouse in IFTM - Campus Uberaba, where the experimental design adopted was the randomized block with six treatments: commercial substrate (T); 100\% vermicompost (T1); 75\% vermicompost +25 sugarcane bagasse (SB) (T2); $50 \%$ vermicompost $+50 \%$ SB (T3); $25 \%$ vermicompost $+75 \%$ SB (T4) e $100 \%$ SB (T5), with four repetitions in trays of 128 cells. Were evaluated fresh and dry matter of shoot and root system, root and shoot length, culm diameter, number of leafs and Dickson Quality Index (DQI). Were observed significative effects of the substrate for all the analyzed characteristics. T5 presented inferior to all characteristics, especially for number of leafs. However, the means of $\mathrm{T}, \mathrm{T} 1$, and $\mathrm{T} 2$ were superior for root fresh matter, while for the other characteristics the same treatments showed equally efficient to T3 and T4. The commercial substrate was not inferior to any characteristic, such as T1, T2 and T3. Therefore, in general, vermicompost was a good alternative at any concentration, but considering all the characteristics evaluated and becoming evident in DQI, the substrates containing from 100 to $75 \%$ of vermicompost, mixed with bagasse, were potentially viable.
\end{abstract}

KEYWORDS: Agroindustrial residues, Alternative substrate, Lycopersicon esculentum Mill.

\section{INTRODUÇÃO}

O tomate sempre recebeu destaque junto às olerícolas pelo seu amplo consumo no Brasil e no mundo, seja in natura (tomate de mesa) ou processado (industrial). Segundo levantamento do IBGE (2017), a produção de tomate no ano de 2017 alcança projeções em torno de 4,3 milhões de toneladas, um crescimento de $18,2 \%$ comparado ao ano de 2016 , incremento beneficiado principalmente pela expansão das áreas produtoras da cultura.

Para o tomate, bem como para a maioria das hortaliças, a propagação via mudas é uma de suas principais características. Segundo Zaccheo et al. (2013), para se obter alta produtividade e frutos de qualidade é necessária a utilização de uma boa técnica de formação de mudas, pois estima-se que $60 \%$ do sucesso de uma cultura está em implantá-la com mudas de qualidade. Esta técnica associada ao uso de substrato orgânico potencializa o sistema de produção (FERREIRA et al., 2014). E, como o uso de insumos é seguramente relevante, o substrato vem ganhando importância devido à sua ampla utilização na produção (FREITAS et al., 2013).

Atualmente o mercado oferece como substrato comercial produtos à base de fibra de coco e casca de pinus ou casca de arroz carbonizada, entretanto o uso é um dos principais fatores de encarecimento da muda. Logo, os estudos por meios alternativos são recorrentes, principalmente aqueles oriundos de reaproveitamento de resíduos.

Dentre o material residual, o produto da vermicompostagem (vermicomposto ou húmus) surge como uma alternativa, que é o processo de reciclagem de resíduos 
orgânicos por meio de criação de minhocas, oferecendo importante alternativa econômica e ambiental para o problema dos dejetos orgânicos, como o lixo domiciliar. O produto final constitui um excelente fertilizante orgânico, capaz de melhorar atributos químicos, físicos e biológicos do solo (EMBRAPA, 2011).

Atiyeh et al. (2000) observaram um incremento de $12,4 \%$ na massa dos frutos do tomateiro produzidos em substrato comercial com $20 \%$ de vermicomposto na composição, em detrimento da testemunha (substrato comercial puro). Enquanto Cerqueira et al. (2015), estudando os efeitos de diferentes substratos sobre a produção de mudas do tomateiro observaram resultados superiores para 0 tratamento apenas com húmus no que se refere à raiz, especialmente volume e massa do sistema radicular. Em outro segmento, Mendoza-Hernández et al. (2014) destacaram o benefício do vermicomposto no enraizamento de estacas de alecrim, atribuindo o efeito à presença de substâncias com atividades hormonais no produto.

A utilização do vermicomposto como substrato tende a seguir formulações onde o composto é misturado a outros orgânicos, assim como o bagaço de cana-deaçúcar. Massad et al. (2016) classificaram o bagaço de cana como produto de grande potencial para produção de mudas de angico-vermelho quando compondo até $75 \%$ da mistura junto à um substrato comercial. A formulação se torna interessante, pois segundo Severino et al. (2006), o bagaço é quimicamente pobre, não sendo recomendado como único componente para composição de substratos. Todavia, o bagaço de cana na composição de substrato para produção de mudas constitui-se em alternativa barata e de fácil disponibilidade (DOS SANTOS et al., 2016).

Diante do exposto, este estudo objetivou avaliar a viabilidade produtiva de mudas de tomateiro produzidas em substrato constituído por vermicomposto e bagaço de cana.

\section{MATERIAL E MÉTODOS}

O experimento foi conduzido em casa de vegetação do Instituto Federal de Educação, Ciência e Tecnologia do Triângulo Mineiro, Campus Uberaba, localizado no município de Uberaba, MG. Localizado em altitude média de $800 \mathrm{~m}$, com latitude

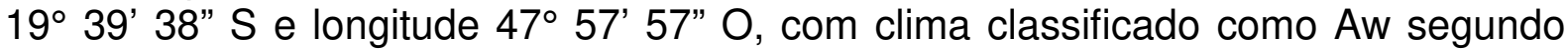
classificação de Koppen, ou seja, quente e úmido com inverno frio e seco.

O delineamento utilizado foi o de blocos ao acaso com 6 tratamentos e 4 repetições, sendo os tratamentos: Substrato comercial constituído por casca de pinus e fibra de coco (testemunha); $100 \%$ de vermicomposto (100V); $75 \%$ de vermicomposto $+25 \%$ de bagaço de cana $(75 \mathrm{~V} / 25 \mathrm{BC}) ; 50 \%$ de vermicomposto + $50 \%$ de bagaço de cana (50V/50BC); $25 \%$ de vermicomposto $+75 \%$ de bagaço de cana $(25 \mathrm{~V} / 75 \mathrm{BC})$ e $100 \%$ de bagaço de cana (100BC). Sendo o vermicomposto oriundo da decomposição de esterco animal por minhocas criadas no setor de minhocultura do IFTM - Campus Uberaba.

Foram preparados cinco litros de cada substrato, segundo as proporções de bagaço de cana e vermicomposto de cada um dos tratamentos que o levam na composição. Após a distribuição, a semeadura foi realizada em bandejas de isopor com 128 células, tendo como objeto de estudo o tomate de mesa, a partir da colocação de duas sementes por célula, com posterior desbaste, aos 24 DAS (dias após semeadura), para manutenção de uma única planta. Cada parcela se constituiu de quatro linhas de cinco células, portanto sendo desconsideradas plantas de bordadura, foram avaliadas seis plantas por parcela. Cada bandeja representou um bloco, totalizando quatro bandejas. 
A avaliação foi realizada aos 36 DAS. As mudas foram removidas das células e tiveram os caules cortados na base, com uso de tesoura, para separação de parte aérea e raiz. Em seguida foi efetuada lavagem do sistema radicular, procedimento cuidadoso iniciado em água corrente e finalizado com a imersão em bacia também com água para remoção completa dos substratos segundo os tratamentos. $\mathrm{Na}$ sequência foram avaliadas as características massa fresca de parte aérea e massa fresca de raiz com utilização de balança de precisão. O diâmetro do coleto foi determinado com auxílio de paquímetro a partir da medição na base do coleto, os comprimentos de parte aérea (altura de planta) e raiz foram mensurados com uso de régua, sendo que a altura da parte aérea foi determinada da base do coleto até o ápice da folha mais alta. Sendo efetuada também a contagem do número de folhas.

As amostras foram dispostas em estufa a $65^{\circ} \mathrm{C}$ até atingirem massas constantes para determinação de massa seca da parte aérea e do sistema radicular. Para determinação da relativa qualidade das mudas foi determinado o Índice de Qualidade de Dickson (IQD), proposto por Dickson et al. (1960) conforme Equação 1.

$$
\mathrm{IQD}=\frac{\mathrm{MST}(\mathrm{g})}{\mathrm{AP}(\mathrm{cm}) / \mathrm{DC}(\mathrm{mm})+\mathrm{MSPA}(\mathrm{g}) / \mathrm{MSR}(\mathrm{g})}
$$

em que:

MST = massa seca total, g;

$\mathrm{AP}$ = altura da parte aérea, $\mathrm{cm}$;

$\mathrm{DC}=$ diâmetro do coleto, $\mathrm{mm}$;

MSPA = massa seca da parte aérea, $g$;

$\mathrm{MSR}=$ massa seca das raízes, $\mathrm{g}$.

Os resultados obtidos foram submetidos à análise de variância. Posteriormente as médias foram comparadas pelo teste de Tukey ao nível $5 \%$ de probabilidade com utilização do software SISVAR $\AA$, além do teste de Dunnett $(0,05)$ para comparação direta dos substratos alternativos com a testemunha.

\section{RESULTADOS E DISCUSSÃO}

Os tratamentos proporcionaram efeitos significativos para todas as características avaliadas $(p<0,05)$. Inicialmente é possível inferir que a massa fresca das mudas, seja de parte aérea ou sistema radicular foi positivamente influenciada pelo incremento do vermicomposto na composição do substrato (Tabela 1), de forma que a raiz obteve médias superiores para as misturas com 100 até $50 \%$ do vermicomposto na composição, em detrimento das demais, enquanto para a parte aérea todos os tratamentos que continham o resíduo da vermicompostagem, independente da porcentagem, produziram maior massa fresca. 
TABELA 1 - Massa fresca de raiz (MFR), massa fresca da parte aérea (MFPA), massa seca de raiz (MSR) e massa seca da parte aérea (MSPA), em $\mathrm{g} /$ planta, de mudas de tomateiro cultivadas em substratos alternativos

\begin{tabular}{llccl}
\hline \multicolumn{1}{c}{ Substrato } & MFR & MFPA $^{1 /}$ & MSR & MSPA $^{1 /}$ \\
\hline $100 \mathrm{~V}$ & $0,319 \mathrm{a}$ & $0,896 \mathrm{a}$ & $0,028 \mathrm{a}$ & $0,075 \mathrm{a}$ \\
$75 \mathrm{~V} / 25 \mathrm{BC}$ & $0,230 \mathrm{ab}$ & $0,575 \mathrm{a}$ & $0,023 \mathrm{a}$ & $0,058 \mathrm{a}$ \\
$50 \mathrm{~V} / 50 \mathrm{BC}$ & $0,185 \mathrm{ab}$ & $0,303 \mathrm{ab}$ & $0,017 \mathrm{ab}$ & $0,039 \mathrm{ab}$ \\
$25 \mathrm{~V} / 75 \mathrm{BC}$ & $0,126 \mathrm{bc}^{*}$ & $0,316 \mathrm{ab}$ & $0,014 \mathrm{ab}^{*}$ & $0,031 \mathrm{ab}$ \\
$100 \mathrm{BC}$ & $0,023 \mathrm{c}^{*}$ & $0,035 \mathrm{~b}^{*}$ & $0,003 \mathrm{~b}^{*}$ & $0,006 \mathrm{~b}^{*}$ \\
\hline Testemunha & $0,288 \mathrm{a}$ & $0,785 \mathrm{a}$ & $0,028 \mathrm{a}$ & $0,078 \mathrm{a}$ \\
\hline \multicolumn{1}{c}{ CV $(\%)$} & 30,47 & 31,95 & 35,65 & 25,68
\end{tabular}

Médias seguidas pela mesma letra não diferem entre si pelo teste de Tukey ao nível de $5 \%$ de probabilidade; "Valores diferentes da Testemunha pelo teste de Dunnett a 0,05 de significância; ${ }^{1 /}$ Análise de variância a partir dos dados transformados por raiz quadrada $(x+1)$.

Um substrato deve apresentar características físicas e químicas que proporcionem condições ideais para o bom desenvolvimento das mudas, resultando em plantas de qualidade (FERREIRA et al., 2014). Em cumprimento à parte dessa premissa, uma justificativa para os resultados supracitados pode ser fundamentada em dados obtidos por Menezes Júnior et al. (2000), que caracterizaram diferentes misturas de substratos e observaram que para um dos dois tratamentos em que 0 vermicomposto foi misturado em maior quantidade (75\% do substrato), a CTC (capacidade de troca catiônica) obtida do composto final foi significativamente superior aos nove outros substratos (incluindo formulações comerciais), com valor de $21,69 \mathrm{cmol}_{\mathrm{C}} \mathrm{dm}^{-3}$, enquanto o outro tratamento obteve a terceira maior CTC, com $17,92 \mathrm{cmol}_{\mathrm{C}} \mathrm{dm}^{-3}$.

Em contrapartida aos benefícios do vermicomposto, como se pode observar, o uso exclusivo do bagaço de cana apresentou médias inferiores, evidenciando a não contribuição, em massa fresca, do resíduo canavieiro quando utilizado sem mistura, especialmente 100BC. Para ambas as massas frescas os melhores desempenhos não diferiram da testemunha. A literatura carece de dados a respeito da massa fresca para estabelecimento de comparações diretas. Entretanto o mesmo não se repete com as demais características.

Em se tratando de massa seca, o teste de médias mostrou a mesma relação da eficiência dos tratamentos para ambos: raiz e parte aérea. Cabendo destacar o tratamento com $100 \%$ de bagaço de cana inferior à testemunha pelo teste de Dunnett $(p<0,05)$ em valores expressivos. A produção de massa seca da parte aérea das mudas em 100BC correspondeu a $7,7 \%$ da produção da testemunha, enquanto a mesma relação para a raiz foi de $10,7 \%$. Resultados que se assemelham aos obtidos por Massad et al. (2016) em estudo sobre misturas de bagaço de cana e substrato comercial em variadas proporções para produção de mudas de angicovermelho. Os autores observaram que o uso de bagaço ocasionou redução na massa fresca da parte aérea, de forma que o tratamento composto exclusivamente pelo resíduo canavieiro foi o único significativamente inferior à testemunha para a característica citada.

Pode-se observar que para as massas apresentadas na Tabela 1, 0 tratamento $100 \mathrm{~V}$ junto às misturas $75 \mathrm{~V} / 25 \mathrm{BC}$ e $50 \mathrm{~V} / 50 \mathrm{BC}$ se apresentaram igualmente eficientes ao substrato comercial. Semelhante, Atiyeh et al. (2000) 
observaram incrementos na massa seca, nos frutos de tomate, quando incorporados 10 ou $50 \%$ de vermicomposto no substrato comercial ainda na fase de muda, em comparação com o tratamento controle, sendo que a incorporação de $20 \%$ gerou a máxima produtividade, demonstrando benefícios que vão além da bandeja. Entretanto, diferente do observado no presente estudo, o vermicomposto adotado isento de mistura gerou efeitos negativos.

O bom desenvolvimento da porção aérea, em especial o número de folhas e comprimento radicular são as características mais importantes no cultivo de mudas, pois são responsáveis pela fotossíntese e absorção de nutrientes (TESSARO et al., 2013). O número de folhas foi influenciado de forma positiva pela presença do vermicomposto, independente da concentração (Tabela 2 ), com médias variando entre 5 a 11 folhas por mudas, contrastando com a média de 100BC, de menos de uma folha por planta $(0,4)$. Steffen et al. (2010) verificaram número de folhas variando entre quatro e cinco em estudo com vermicomposto na produção de mudas de tomateiro, estas avaliadas aos 25 DAS. Vale ressaltar que não houve outra característica em que $100 \mathrm{BC}$ se apresentasse isoladamente inferior aos demais tratamentos.

TABELA 2 - Diâmetro do coleto (DC), altura de planta (AP) e comprimento de raiz (CR), em milímetros, e número de folhas (NF) de mudas de tomateiro cultivadas em substratos alternativos

\begin{tabular}{lrrrc}
\hline \multicolumn{1}{c}{ Substrato } & NF $^{1 /}$ & DC & AP & CR \\
\hline $100 \mathrm{~V}$ & $11 \mathrm{a}$ & $1,95 \mathrm{a}$ & $102,63 \mathrm{a}$ & $85,52 \mathrm{ab}$ \\
$75 \mathrm{~V} / 25 \mathrm{BC}$ & $9 \mathrm{a}$ & $1,76 \mathrm{a}$ & $82,00 \mathrm{ab}$ & $96,19 \mathrm{a}$ \\
$50 \mathrm{~V} / 50 \mathrm{BC}$ & $6 \mathrm{a}$ & $1,37 \mathrm{ab}$ & $55,00 \mathrm{ab}$ & $92,67 \mathrm{ab}$ \\
$25 \mathrm{~V} / 75 \mathrm{BC}$ & $5 \mathrm{a}$ & $1,29 \mathrm{ab}$ & $59,13 \mathrm{ab}$ & $88,89 \mathrm{ab}$ \\
$100 \mathrm{BC}$ & $0,4 \mathrm{~b}^{*}$ & $0,68 \mathrm{~b}^{*}$ & $33,50 \mathrm{~b}^{*}$ & $62,20 \mathrm{~b}^{*}$ \\
\hline Testemunha & $9 \mathrm{~A}$ & $1,71 \mathrm{a}$ & $86,13 \mathrm{ab}$ & $94,39 \mathrm{a}$ \\
\hline \multicolumn{1}{c}{ CV $(\%)$} & 16,44 & 22,48 & 35,39 & 15,33 \\
\hline
\end{tabular}

Médias seguidas pela mesma letra não diferem entre si pelo teste de Tukey ao nível de $5 \%$ de probabilidade; *Valores diferentes da Testemunha pelo teste de Dunnett a 0,05 de significância;

${ }^{1 /}$ Análise de variância a partir dos dados transformados por raiz quadrada $(x+1)$.

Foi possível notar a influência do substrato sobre o comprimento de raiz. A mistura $75 \mathrm{~V} / 25 \mathrm{BC}$ e 0 substrato comercial geraram efeitos benéficos no alongamento radicular, pois mesmo que não se apresentem diferentes de $100 \mathrm{~V}$, $50 \mathrm{~V} / 50 \mathrm{BC}$ e $25 \mathrm{~V} / 75 \mathrm{BC}$, as médias destes tenderam, também, a não diferir de 100BC, com média 35\% inferior à maior média. Tal resposta pode ser atribuída, dentre outros fatores à porosidade do substrato, que facilitou a penetração radicular e seu desenvolvimento. O tratamento $75 \mathrm{~V} / 25 \mathrm{BC}$ tem $25 \%$ de bagaço de cana que acrescem em porosidade ao conteúdo nutricional oriundo do vermicomposto e, conforme esse conteúdo decaiu, não se obteve a mesma resposta nos demais tratamentos.

Também o tratamento 100BC se mostrou inferior à testemunha pelo teste de Dunnett $(p<0,05)$ em diâmetro do coleto, altura de plantas e comprimento de raiz. Entretanto o teste de Tukey não aponta diferença entre 100BC, 25V/75BC e 25V/75BC para diâmetro do colmo, apesar dos dois últimos também não diferirem das maiores médias, de $100 \mathrm{~V}(1,95 \mathrm{~mm}), 75 \mathrm{~V} / 25 \mathrm{BC}(1,76 \mathrm{~mm})$ e substrato comercial $(1,71 \mathrm{~mm})$. De forma semelhante, dos Santos et al. (2010) encontraram médias 
superiores para tratamentos com $100 \%$ de vermicomposto $(1,66 \mathrm{~mm}), 75 \%$ vermicomposto $+25 \%$ vermiculita $(1,65 \mathrm{~mm})$ e substrato comercial $(1,77 \mathrm{~mm})$, estes na produção de mudas de pimentão.

Steffen et al. (2010) apresentaram médias de altura de mudas de tomate variando entre 54,75 e 99,25 mm em estudo com vermicomposto, valores que conferem com os observados na Tabela 2 e com destaque para o tratamento $100 \mathrm{~V}$, que deu pleno suporte ao crescimento das plantas em altura. Essa observação pode ser complementada com as massas seca e fresca da parte aérea encontradas para o mesmo tratamento, apresentadas anteriormente, com 0,896 g/planta (MFPA) e $0,075 \mathrm{~g} /$ planta (MSPA).

Pode-se observar ao utilizar o Índice de Qualidade de Dickson (Figura 1), que a qualidade da muda segue os padrões que as características anteriormente sugeriam. Lembrando que o índice leva em consideração a massa seca total, a altura da parte aérea, o diâmetro do coleto, a massa seca da parte aérea e a massa seca das raízes e que a qualidade da muda é dada de forma proporcional ao aumento do valor de IQD. Valores superiores supõem que a muda possui características como vigor necessário para ser transplantada sem efeito adverso.

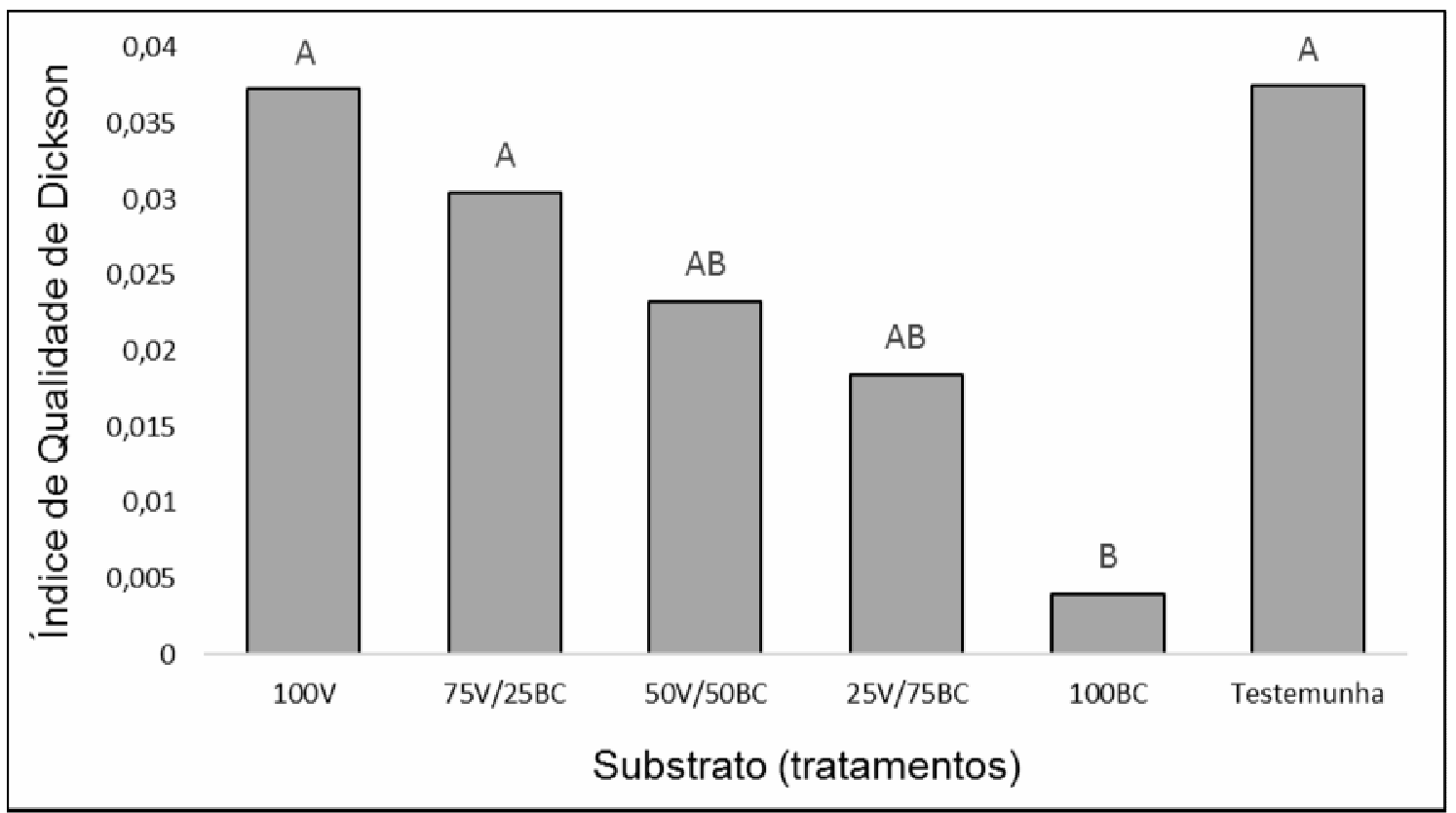

FIGURA 1 - Gráfico da qualidade de mudas segundo índice desenvolvido por DICKSON et al. (1960). Colunas seguidas por mesma letra maiúscula não diferem entre si pelo teste de Tukey $(p<0,05)$.

Melo et al. (2012) constataram que o húmus de minhoca influenciou o crescimento inicial de mudas tipo pé-franco de tamarindeiro, apresentando melhores resultados à medida que aumenta a proporção é possível inferir que o vermicomposto em maiores proporções foi tão eficiente quanto o material usado como testemunha, com índices de 0,0373 (100V), 0,0305 (75V/25BC) e 0,0375 (substrato comercial). Conforme se reduz o vermicomposto (ou aumenta o bagaço de cana), a média tende à redução, apesar da estatística de Tukey não apresentar diferenças entre 50V/50BC $(0,0232)$ e 25V/75BC $(0,0185)$ para as maiores médias. Porém as mesmas não se mostraram inferiores à menor média, do tratamento composto por $100 \%$ de bagaço de cana com IQD igual a $0,0040,89 \%$ inferior à testemunha. 
Dessa forma, nas condições estudadas, o bagaço de cana não supriu a demanda nutricional da planta, pela baixa superfície específica, em oposição ao vermicomposto, mas também pela maior relação $\mathrm{C}: \mathrm{N}$ do material, que exige um período mais longo para mineralização dos nutrientes contidos no resíduo vegetal. Isso não exclui todos os benefícios do material, pois como foi observado, junto ao vermicomposto e principalmente na proporção $75 \mathrm{~V} / 25 \mathrm{BC}$, o bagaço de cana contribuiu com o alongamento radicular da muda, essencial para o estabelecimento no campo.

Considerando que a escolha de um substrato hortícola deve ser baseada em dois critérios essenciais: o custo de aquisição e a disponibilidade do material para produção do substrato (STEFFEN et al., 2010) e levando em conta todas as características analisadas, os tratamentos $100 \mathrm{~V}$ e $75 \mathrm{~V} / 25 \mathrm{BC}$ se apresentaram as melhores alternativas dentre as estudadas.

\section{CONCLUSÕES}

O substrato comercial deu pleno suporte ao desenvolvimento das mudas. Considerando esse fator, os tratamentos com $100 \%$ vermicomposto e $75 \%$ vermicomposto $+25 \%$ bagaço de cana se mostraram potenciais alternativas para produção de mudas de tomateiro como forma de reduzir custos de aquisição.

O bagaço de cana utilizado sem mistura não se mostrou eficiente para nenhuma característica avaliada.

\section{REFERÊNCIAS}

ATIYEH, R. M.; ARACON, N.; EDWARDS, C. A.; METZGER, J. D. Influence of earthworm-processed pig manure on the growth and yield of greenhouse tomatoes. Bioresource Technology, v. 75, n. 3, p. 175-180, 2000. Disponível em: <https://doi.org/10.1016/S0960-8524(00)00064-X> . doi: 10.1016/S09608524(00)00064-X.

CERQUEIRA, F. B.; FREITAS, G. A.; MACIEL, C. J.; CARNEIRO, J. S. S.; LEITE, R. C. Produção de mudas de tomate cv. Santa cruz em diferentes substratos. Journal of Bioenergy and Food Science, v. 2, n. 2, p. 39-45, 2015. Disponível em: $<279213489$ Producao_de_mudas_de_tomate_cv_Santa_Cruz_em_diferentes_sub stratos>. doi: 10.18067/jbfs.v2i2.21.

DICKSON, A.; LEAF, A. L.; HOSNER, J. F. Quality appraisal of white spruce and white pine seedling stock in nurseries. The Forestry Chronicle, v. 36, n. 1, p. 1013,1960. Disponível em: <https://doi.org/10.5558/tfc36010-1>. doi: 10.5558/tfc360101 .

DOS SANTOS, A. R.; MENEZES, E. S.; MASSAD, M. D.; DUTRA, T. R.; AGUILAR, M. V. M. Utilização de bagaço de cana na produção de mudas de Pterogyne nitens Tul. Blucher Engineering Proceedings, v. 3, n. 2, p. 1009-1015, 2016. Disponível em: $<$ http://pdf.blucher.com.br.s3-sa-east1.amazonaws.com/engineeringproceedings/eneeamb2016/rs-022-4993.pdf>. doi: 10.5151/engpro-eneeamb2016-rs-022-4993.

DOS SANTOS, M. R.; SEDIYAMA, M. A. N.; SALGADO, L. T.; VIDIGAL, S. M.; REIGADO, F. R. Produção de mudas de pimentão em substratos à base de vermicomposto. Bioscience Journal, v. 26, n. 4, p. 572-578, 2010. Disponível em: 
$<$ http://www.seer.ufu.br/index.php/biosciencejournal/article/view/7147>. Acesso em: 05 ago. 2017.

EMBRAPA. Empresa Brasileira de Pesquisa Agropecuária - Embrapa Agrobiologia. Minhocultura ou vermicompostagem. 2011. Disponível em: $<$ https://www.embrapa.br/documents/1355054/1527012/4b+-

+folder+Minhocultura+ou+vermicompostagem. pdf/323fbedc-7b3c-4d89-bccd70b490b8e88b>. Acesso em: 11 ago. 2017.

FERREIRA, L. L.; ALMEIDA, A. E. S.; COSTA, L. R.; BEZERRA, F. M. S.; LIMA, L. A.; PORTO, V. C. N. Vermicompostos como substrato na produção de mudas de berinjela (Solanum melongena) e pimentão (Capsicum annumm). Holos, v. 4, p. 269-277. 2014. Disponível em: <http://www.redalyc.org/html/4815/481547173024/>. doi: 10.15628/holos.2014.1409.

FREITAS, G. A.; SILVA, R. R.; BARROS, H. B.; VAZ-DE-MELO, A.; ABRAHÃO, W. A. P. Produção de mudas de alface em função de diferentes combinações de substratos. Revista Ciências Agronômicas, v. 44, n. 1, p.159-166, 2013. Disponível em: <http://dx.doi.org/10.1590/S1806-66902013000100020>. doi: 10.1590/S1806-66902013000100020.

IBGE. Instituto Brasileiro de Geografia e Estatística. Levantamento Sistemático da Produção Agrícola (LSPA). 2017. Disponível em: <ftp://ftp.ibge.gov.br/Producao_Agricola/Levantamento_Sistematico_da_Producao_A gricola_[mensal]/Fasciculo/lspa_201706.pdf>. Acesso em: 05 ago. 2017.

MASSAD, M. D.; DUTRA, T. R.; CARDOSO, R. L. R.; SANTOS, T. B.; SARMENTO, M. F. Q. Produção de mudas de Anadenanthera peregrina em resposta a substratos alternativos com bagaço de cana. Revista Ecologia e Nutrição Florestal, v. 4, n. 2, p. 45-53, 2016. Disponível em: <http://dx.doi.org/10.5902/2316980X24308>. doi: $10.5902 / 2316980 \times 24308$.

MELO, I. G. C.; GÓES, G. B.; DANTAS, D. J.; DE ARAÚJO, W. B. M.; ALENCAR, R. D. Utilização de húmus de minhoca como substrato na produção de mudas de tamarindeiro. Revista Verde de Agroecologia e Desenvolvimento Sustentável, v. 6, n. $\quad 4$ p. 125-131, 2012. Disponível em: <http://dx.doi.org/10.18378/rvads.v6i4.495>. doi: 10.18378/rvads.v6i4.495.

MENDOZA-HERNÁNDEZ, D.; FORNES, F.; BELDA, R. M. Compost and vermicompost of horticultural waste as substrates for cutting rooting and growth of rosemary. Scientia Horticulturae, v. 178, p. 192-202, 2014. Disponível em: <https://doi.org/10.1016/j.scienta.2014.08.024>. doi: 10.1016/j.scienta.2014.08.024.

MENEZES JÚNIOR, F. O. G.; FERNANDES, H. S.; MAUCH, C. R.; SILVA, J. B. Caracterização de diferentes substratos e seu desempenho na produção de mudas de alface em ambiente protegido. Horticultura Brasileira, v. 18, n. 3, p. 164-170, 2000. Disponível em: <http://dx.doi.org/10.1590/S0102-05362000000300004>. doi: $10.1590 /$ S0102-05362000000300004. 
SEVERINO L. S.; LIMA, R. DE L. S. DE; BELTRÃO, N. E. DE M. Composição química de onze materiais orgânicos utilizados em substratos para produção de mudas. Campina Grande: Embrapa, 2006. (Comunicado técnico, n. 27).

STEFFEN, G.P.K.; ANTONIOLLI, Z.I.; STEFFEN, R.B.; MACHADO, R.G. Casca de arroz e esterco bovino como substratos para a multiplicação de minhocas e produção de mudas de tomate e alface. Acta Zoológica Mexicana, Número Especial 2, p.333-34, 2010. Disponível em: <http://www.scielo.org.mx/scielo.php?script=sci_arttext\&pid=S006517372010000500025>. doi: 0065-1737/S0065-17372010000500025.

TESSARO, D.; MATTER, J. M.; KUCZMANI, O.; FURTADO, L. M.; COSTA, L. A. D. M.; \& COSTA, M. S. S. M. Produção agroecológica de mudas e desenvolvimento a campo de couve-chinesa. Ciência Rural, v. 43, n. 5, p. 831-837, 2013. Disponível em: <http://dx.doi.org/10.1590/S0103-84782013005000036>. doi: 10.1590/S010384782013005000036 .

ZACCHEO, P. V. C.; AGUIAR, R. S.; STENZEL, N. M. C.; NEVES, C. S. V. $J$. Tamanho de recipientes e tempo de formação de mudas no desenvolvimento e produção de maracujazeiro-amarelo. Revista Brasileira de Fruticultura, v. 35, p. 603-607, 2013. Disponível em: <http://dx.doi.org/10.1590/S0100$29452013000200032>$. doi: 10.1590/S0100-29452013000200032. 